Maiolino, A.L.; Mancebo, D. "Análise histórica da desigualdade: marginalidade, segregação e exclusão"

\title{
ANÁLISE HISTÓRICA DA DESIGUALDADE: MARGINALIDADE, SEGREGAÇÃO E EXCLUSÃO
}

\author{
Ana Lúcia Gonçalves Maiolino \\ Deise Mancebo \\ Universidade do Estado do Rio de Janeiro
}

\begin{abstract}
RESUMO: O trabalho tem como objetivo a discussão da produção acadêmica sobre a temática da exclusão, verificando suas enunciações e usos, ao longo dos últimos 30 anos. Para tanto, é retomada a discussão sobre a marginalidade, típica da década de 1970. A década seguinte é apresentada através de autores e análises que apontam para o território e o espaço enquanto direitos do cidadão para, por fim, apresentar alguns problemas vinculados ao uso generalizado do conceito de exclusão social, bem como sua eventual aderência ao mundo globalizado.

Palavras-chave: Desigualdade; marginalidade; exclusão; cidades duais.
\end{abstract}

\section{HISTORICAL ANALYSIS OF INEQUALITY: MARGINALITY, SEGREGATION AND EXCLUSION}

ABSTRACT: The paper proposes the reflection on the academic prodution about exclusion, verifying its enunciations and uses, during the last thirty years. It resumes the arguments about the marginality, which was typical of the seventies. The following decade is presented through authors and discussions that aim to analyse the territory and the space as the citizen's right. Finally, it focuses on some problems related to the generalized use of the concept of social exclusion, as well as its eventual adhesion to the global world.

Key-words: Inequality; Marginality; Exclusion; Dual Cities

A literatura acadêmica e jornalística, produzida na última década, vem, de maneira geral, enfatizando a polarização que parece dominar as sociedades modernas. A forte imagem de ilhas privilegiadas nas cidades, destacando-se de vastas regiões empobrecidas tanto econômica quanto intelectualmente, acaba por instituir como verdade uma situação de dualidade radical no tecido urbano, onde as gradações parecem não ter mais lugar.

Fala-se de exclusão e há uma autorização praticamente consensual para que aí estejam inseridas, de forma amalgamada, exclusões cultural, espacial, social e econômica. Nessa linha de raciocínio, os habitantes pobres da periferia constituem-se, a priori, como indivíduos marcados por essas exclusões, subjetivando-se como os de fora.

Nosso questionamento, no momento, é se essas premissas são razoáveis para se pensar a cidade. Desconfiamos da generalidade dessas análises e tememos que elas possam estar simplificando a complexa e múltipla realidade urbana. Assim, este trabalho tem como objetivo enfocar uma pequena parcela deste intrincado problema: propomo-nos a delimitar, mais detalhadamente, a produção acadêmica sobre a temática da exclusão, verificando suas enunciações e usos, ao longo dos últimos 30 anos. Para tanto é retomada a discussão sobre a marginalidade, típica da década de 1970. A década seguinte é apresentada através de autores e análises que apontam para o território e o espaço enquanto direitos do cidadão para, por fim, apresentarmos alguns problemas vinculados ao uso generalizado do conceito de exclusão social, bem como sua eventual aderência ao mundo globalizado.

\section{CAPITALISMO E MARGINALIDADE: A DISCUSSÃO NA DÉCADA DE 1970}

A palavra [marginalidade] introduziuse em nosso meio como referência a certos problemas surgidos no processo de urbanização posterior à Segunda Guerra Mundial, como conseqüência do estabelecimento de núcleos de populações recentes e de características sub-standard na periferia do corpo urbano tradicional da maior parte das cidades latinoamericanas. ... Como, precisamente, esses povoamentos se levantaram, em regra geral, nas bordas ou margens do corpo urbano tradicional das cidades, o mais fácil era denominá-los "bairros marginais" e seus habitantes, "populações marginais". ... O problema que estes grupamentos encerravam se constituiu no problema das "populações mar- 
ginais. (Quijano, 1978, p. 18)

Este texto de Anibal Quijano, publicado primeiramente em outubro de 1966, para uma discussão interna da Comissão Econômica para a América Latina e o Caribe (CEPAL), circunscreve de forma clara não apenas a origem do termo marginal, mas também sua vinculação à questão do crescimento acelerado e desigual das grandes cidades, ocorrido, sobretudo, a partir da década de 1950.

Prossegue o autor, ressaltando que logo se descobre que moradias precárias não se encontravam apenas nas áreas marginais, mas também eram localizáveis nos setores mais centrais e tradicionais das cidades. Além desse fato, verifica que "não era unicamente a moradia ou a habitação como tais que se encontravam em precariedade, mas todo o conjunto de 'serviços comunais' (água, esgoto, luz elétrica, transportes) de certas áreas da cidade" (Quijano, 1978, p. 19).

Além de Quijano, muitos autores passam a fazer uso corrente do conceito e, conseqüentemente, diversas variantes de utilização do termo se integram às análises acadêmicas, especialmente, nos anos 1970. Dentre outras representações, eram encontradas abordagens que tomavam a marginalidade como uma situação ecológica, referida à falta de integração destes núcleos "em relação aos serviços comunais que caracterizam a ecologia urbana das cidades" (Quijano, 1978, p. 20); análises que privilegiavam a marginalidade como participação na cultura da pobreza, neste caso, associada a um fenômeno psicológico-social, que se caracterizaria por sentimentos ambivalentes de não pertencimento e, ao mesmo tempo, de dependência, o que remeteria a uma carência de identidade sócio-cultural; formulações nas quais a marginalidade era tomada como fruto de um atraso no desenvolvimento econômico, vinculada à noção de que no processo de desenvolvimento econômico dos países subdesenvolvidos, alguns grupos sempre permanecem à margem dos benefícios materiais e culturais alcançados pela sociedade nacional.

Diante da impossibilidade de se expor as várias concepções de marginalidade em vigor no período em questão, pode-se afirmar que duas grandes correntes sociológicas embasavam essas análises: o estruturalismo funcionalista e o estruturalismo histórico. O núcleo conceitual do estruturalismo funcionalista situava-se na noção de "sistema social", entendido como um consenso, uma funcionalidade universal dos elementos que constituiriam a estrutura de uma sociedade, admitindo, portanto, uma certa harmonia e continuidade unindo os vários segmentos sociais. Sob essa perspectiva, toda existência marginal se configuraria numa forma, ao menos em parte, não integrada à sociedade, carecendo de certos ajustes setoriais que facilitassem a adaptação-integração.Tratava-se de desorganizações transitórias que, em analogia aos processos metabólicos dos organismos biológicos, poderiam ser assimiladas, sem a necessidade de maiores alterações sociais estruturais e sem modificações nas tendências fundamentais da própria sociedade (Quijano, 1978; Véras, 1999). Muitas análises desenvolvidas no Brasil em torno da pobreza urbana, compartilharam dessa perspectiva teórica, atribuindo, p. ex. , ao massivo êxodo rural para o sudeste, a responsabilidade pelos problemas enfrentados nas grandes cidades, fossem eles de moradia, mendicância, delinqüência, dentre outros. Esta vertente subsidiava, portanto, uma visão dualista da sociedade que oporia ao setor desenvolvido da sociedade um outro, marginal e não funcional, mas metabolizável, mediante a adoção de políticas específicas.

O estruturalismo histórico, por seu turno, mesmo admitindo a associação funcional de alguns núcleos de elementos da sociedade, considerava que a integração da sociedade ocorre, preponderantemente, de maneira conflituosa e descontínua, enfatizando a importância das circunstâncias históricas, que determinam a incorporação dos diversos elementos à estrutura social. Nestas circunstâncias, "a existência marginal de um determinado elemento ou conjunto de elementos pode ser o resultado da natureza mesma da estrutura vigente da sociedade" (Quijano, 1978, p. 31). Sob essa ótica, a pobreza estava enraizada às próprias contradições do modo de produção capitalista. Os mesmos migrantes eram, sob essa perspectiva, apresentados como elementos de um exército industrial de reserva, formação não-marginal, mas integrada às engrenagens produtivas de forma desigual (Kowarick, 1975).

No América Latina, na década de 1970, esta visão estruturalista histórica se estabelece como a hegemônica, concentrando os debates sobre a marginalidade. As sociedades dependentes dos países subdesenvolvidos e em desenvolvimento se configurariam como as que estariam, mais intensamente, submetidas a uma integração conflituosa, dada a sua constituição a partir de fatores históricos muito diferenciados, que dificultariam o desenvolvimento de um processo mais congruente de integração. Os trabalhos de Nun, em 1969, e de Quijano, em 1970, citados em Berlink (1975) ${ }^{1}$, são exemplares dessa linha teórica, pois defendem a especificidade do conceito de marginalidade, rechaçando, todavia, a visão dualista, própria ao funcionalismo.

Esta discussão logo foi assumida por diversos autores brasileiros, convergindo para a noção de que o sistema capitalista, nos países periféricos, não resultou de duas formas produtivas estanques, "uma dinâmica e a outra que constituiria um 'peso morto' no 
processo de geração de riquezas" (Kowarick, 1975, p. 83), mas que uma única lógica estrutural capitalista reunia formas desiguais e combinadas de produção, que guardariam estreita relação com o ciclo de expansão do capital.

Além disto, autores como Kowarick (1975) e Berlink (1975) questionavam a amplitude do termo marginalidade, que rapidamente havia acolhido uma variedade de situações e problemas e, em conseqüência, perdera em clareza conceitual e analítica. Partem para uma utilização mais circunscrita do conceito - e o estruturalismo histórico em muito auxiliava neste intento -, passando a equacioná-lo em termos do processo de inserção ou não dos trabalhadores no sistema produtivo capitalista ${ }^{2}$.

Um outro ponto importante destes estudos da década de 1970 diz respeito à estreita relação que o conceito de marginalidade acaba estabelecendo com a formulação marxiana do exército industrial de reserva. Cabe lembrar que o exército industrial de reser$v a$ serve ao capitalismo de duas formas: em seus momentos de expansão, provendo a necessária mão-deobra requerida ao crescimento da produção, e, em todos os momentos, como um fator de controle do custo da mão-de-obra, na medida em que o excedente de trabalhadores e a competição entre estes pressionariam os salários para baixo, reduzindo-os. Assim, as chamadas populações marginais manteriam com a sociedade a que pertencem uma relação de participação, qual seja, participam do mercado de trabalho como ofertantes de mão-de-obra, garantindo uma maior acumulação do capital.

Toda esta discussão dos anos 1970 apresenta muitos meandros, argumentos e contra-argumentos, que não são passíveis de serem explorados no âmbito deste texto. Cabe ressaltar, contudo, que as análises do fenômeno da marginalidade ativeram-se à avaliação das formas de inserção dos trabalhadores no modo produtivo capitalista periférico e no próprio entendimento da forma de desenvolvimento deste capitalismo periférico. Em resumo, o esforço central da análise era compreender a marginalidade no âmbito da estrutura do capitalismo, desprezando, até certo ponto, as análises que identificavam o centro do problema na questão da integração ou não integração em seus aspectos psíquicos e sociais ou mesmo na avaliação da produção da pobreza e dos poderes de consumo desta ou daquela parcela das populações. Ademais, destaca-se como outro ponto comum a todas estas produções a crítica veemente à visão dualista dos rumos das sociedades capitalistas.

\section{SEGREGAÇÃO URBANA E CIDADANIA: A DISCUSSÃO DA DÉCADA DE 1980}

Nos anos 1980, novas inflexões e temáticas são acrescidas à discussão. Pode-se dizer que, sob a inspiração da transição democrática, no calor do crescimento dos movimentos populares, enfim, diante da própria reorganização da sociedade civil brasileira, o enfoque da discussão sobre a marginalidade muda. As análises sobre a pobreza, suas características e causas, as pesquisas sobre favelados e sobre a imigração como emblemas da exclusão nas cidades, tudo isso muda de tom para a consideração da marginalidade como cidadania limitada, vista como resultado da dificuldade desses grupos em participarem do processo de desenvolvimento econômico e de ascensão social. Assim, as temáticas que passam a ocupar a cena acadêmica são aquelas "da democracia, da segregação urbana, a importância do território para a cidadania, a falência das ditas políticas sociais, os movimentos sociais, as lutas sociais" (Véras, 1999, p. 31). O eixo norteador, adotado por diversos autores, passa a ser o território e os direitos do cidadão.

Milton Santos (1987) é emblemático nessa discussão e, de certo modo, pode ser tomado como uma síntese das discussões críticas do período. Por um lado, o autor chamava atenção para o direito que o cidadão deveria ter à mobilidade espacial e ao acesso a serviços públicos, questionando assim a fixação da pobreza em determinados espaços. Ao mesmo tempo, advogava o direito do cidadão permanecer no seu lugar identitário, criticando com isso a descaracterização de bairros, a expulsão de favelados, os despejos e o "nomadismo sem direito às raízes" (Véras, 1999, p. 33), tão próprio das políticas urbanas atreladas aos interesses do mercado e do capitalismo predatório. Assim, Santos destacava dois aspectos, aparentemente contraditórios, das dinâmicas urbanas, mas que apresentam em comum o fato de remeterem à defesa da cidadania, marca principal das discussões dessa década.

\section{GLOBALIZAÇÃO E A EXCLUSÃO SOCIAL: EM PAUTA A DÉCADA DE 1990}

Na década de 1990, novas inflexões podem ser observadas. Os discursos já não se referem à marginalidade, mas passam a utilizar, de forma abundante, as noções de segregação social e, principalmente, de exclusão social.

A influência do pensamento francês foi decisiva na adoção generalizada deste último termo, que se refere, conforme o autor e ao tom da análise, tanto a causas, processos ou a situações conseqüentes, aparecendo, com freqüência, combinada às análises sobre o desmonte do Estado do Bem Estar Social. Castel (1998), p. ex., tornou-se uma referência para esse debate, com a utilização do termo desfiliação, com o qual se refere tanto ao aumento da exclusão do em- 
prego, mas também à precarização das relações contratuais e das formas de sociabilidade ${ }^{3}$.

No Brasil, o uso da exclusão também ganhou adeptos. Conforme observado por Nascimento (1994), autores como Hélio Jaguaribe, ainda na década de 1980, e Cristóvam Buarque, em 90, entendem as desigualdades como formas perversas da crise econômica, que se estabelecem a partir do fim do "milagre brasileiro", constituindo-se em caos e ameaça à paz social. Ainda segundo o autor, a idéia de dualização social retorna, de modo preponderante, com ênfase na noção de que existem pobres cada vez mais miseráveis, numerosos e ousados e, por outro lado, ricos minoritários e temerosos.

Nas expressões desigualdade, discriminação e segregação, os membros dos grupos referenciados são menores, inferiores, subordinados, mas tomam parte do mesmo universo, da mesma sociedade. Como vimos, para os que adotam o estruturalismo histórico, eles apresentam uma positividade para o sistema, constituindo, conforme a análise, um exército de reserva. No entanto, as noções de exclusão ou apartação contêm, de forma mais ou menos implícita, a idéia de partição e de separação. Assim, a dualização retorna ao centro da análise sociológica e, agora, com maior intensidade, do que tinha se visto no estruturalismo funcional. As análises críticas atuais, que se baseiam na exclusão, já não acreditam na possibilidade dos desvios serem metabolizados e re-assimilados - pressuposto do funcionalismo -, pelo menos no marco do capitalismo, até porque a exclusão abrange contingentes cada vez maiores da população. A citação de Boaventura de Souza Santos (1999) é elucidativa do que queremos destacar:

A economia foi socializada em pequenas ilhas de inclusão que passaram a existir em vastos arquipélagos de exclusão; a politização do Estado cedeu freqüentemente à privatização do Estado e à patrimonialização da dominação política ... O regime geral de valores parece não resistir à crescente fragmentação da sociedade, dividida em múltiplos apartheids, polarizada ao longo de eixos econômicos, sociais, políticos e culturais (Santos, 1999, p. 40).

Nesse ponto da nossa exposição, gostaríamos de levantar uma hipótese para a utilização tão intensa do termo exclusão no atual contexto: a crise do Estado Providência; seu fracasso na obtenção da igualdade de acesso a serviços sociais; o apregoamento do Estado Mínimo, que admite as desigualdades como responsabilidade do próprio cidadão e considera o diferente como inútil economicamente, são alguns dos elementos que elevam a recorrência das análises so- bre exclusão. "Estar fora, ser diferente, não se submeter às normas homogeneizadoras, é estar excluído ou ‘empurrado' para fora” (Véras, 1999, p. 37). A exclusão social apareceria como a face rejeitada do neoliberalismo globalizado, para cujos integrantes não há nenhuma política assistencialista, como se as classes dominantes houvessem desistido de integrar essas parcelas à produção ou à cidadania. No lugar da idéia de um exército industrial de reserva, que destinaria aos marginais uma alta positividade para o funcionamento mais geral do sistema de exploração, teríamos a idéia do estorvo, da exclusão, a imputação de uma sub-humanidade aos grupos, cada vez mais numerosos de excluídos, para quem não se teria um lugar peculiar no mundo (Arendt, 1990), diante da falência assumida do processo de integração social.

São vários os argumentos em defesa do retorno da dualização social, e um dos mais fortes parte daqueles que detectam um crescimento acentuado nos níveis de desemprego, na deterioração das próprias condições de trabalho, dos vínculos empregatícios menos estáveis (trabalhos temporários e autônomos) para parcelas cada vez maiores da população. Em adição, o que também parece marcante é o fato de que tais tendências são verificadas tanto nas economias mais fracas e dependentes quanto naqueles países em que o capitalismo já atingira formas mais avançadas, indicando uma certa mundialização dos problemas relacionados ao emprego. Assim, o que estaria ocorrendo no mundo globalizado seria uma tendência à restrição da mobilidade social ascendente, verificando-se, em contraposição, contingentes cada vez mais expressivos de indivíduos que passariam a ocupar posições mais baixas na escala social. Ora, se a mobilidade social tende a ser esmagadoramente descendente, podemos pensar que estamos em presença de uma situação de exclusão e não mais apenas de desigualdade social.

Seguindo esse raciocínio, o uso do conceito de exclusão social assume também a função de demarcação de uma posição política e ideológica contrária aos rumos da globalização, reforçando determinadas argumentações sobre as conseqüências perversas da economia atual, a despeito da imprecisão conceitual do termo. Observa-se, neste sentido, que são nomeados excluídos diferentes categorias, tais como as populações de rua, os desempregados, os pobres, os que habitam a periferia, os que habitam os morros, os que têm baixo grau de instrução e assim por diante.

Evidencia-se, portanto, que não apenas o desemprego se encontra atrelado ao discurso sobre a exclusão social. Ao contrário, assim como na década de 1970 a marginalidade abrangeu uma grande gama de questões, conforme evidenciado por Quijano 
(1978), também a exclusão social vem sendo referenciada a diversos aspectos da vida social e da economia, abrangendo desde as minorias (negros, homossexuais, deficientes), assim como desempregados, pobres, sem-teto, catadores de lixo, meninos de rua ... Mais do que isto, a exclusão social vem sendo objeto de interesse para diferentes áreas da produção do conhecimento 4 .

E este é o caso de alguns autores que têm utilizado o conceito de exclusão para a análise das grandes cidades. Apontam, assim, uma dualização social ou uma polarização social, em cujo processo as classes médias tenderiam a diminuir. À metáfora da pirâmide, representativa da hierarquia num contexto fordista, teríamos a representação da sociedade contemporânea através de uma ampulheta, com dois pólos configurados e com os seus extratos médios progressivamente se estreitando. Para grande parte da literatura crítica atual sobre o espaço urbano, esta dualização apresentaria correlatos espaciais, de modo que a apropriação do espaço urbano também tenderia à exclusão e a uma configuração polarizada entre ricos e pobres.

\section{SEGREGAÇÃO ESPACIAL? EM FOCO A REGIÃO ME-} TROPOLITANA DO RIO DE JANEIRO

Conforme abordado por Ribeiro (2000a), o modelo das "cidades globais" pressupõe a substituição da complexa estrutura de classe da cidade industrial por uma estrutura polarizada entre pobres e ricos, onde se dispõe, de um lado, ...

[...de] um grande contingente de trabalhadores dos serviços de pouca qualificação e baixa remuneração e de desempregados vivendo de 'viração', e [de outro], um pequeno segmento constituído pelos novos profissionais da economia de serviços e financeira ... altamente qualificados e muito bem remunerados. (p.16)

Ainda segundo o autor, este modelo preconiza que, em continuidade à dualização da estrutura social, ocorreria o estabelecimento de uma nova ordem urbana, com os espaços fragmentados, como resultado do "aumento da segregação urbana e das desigualdades sociais" (Ribeiro, 2000a, p. 16).

Duas seriam as argumentações básicas que sustentariam estas considerações: a crise de governabilidade das cidades ${ }^{6}$ e a reestruturação produtiva, que levaria a uma expansão das classes superiores e inferiores e a uma contração das classes médias.

No entanto, esta análise mais geral das cidades globais não tem resistido a algumas pesquisas empíricas. Ribeiro (2000a) cita que investigações re- alizadas, na década de 1990, para as cidades de Londres e Paris ${ }^{7}$ não confirmam esta tese da dualização das estruturas sociais e espaciais, muito embora confirmem "o crescimento das desigualdades sociais em termos de renda" (p. 66). Quanto às classes médias, também não foi detectada uma contração, mas uma importante reconfiguração, com o "desaparecimento de algumas [profissões], a desqualificação de outras e, ao mesmo tempo, o surgimento de novas profissões ligadas à expansão das funções de gestão" (Ribeiro, 2000b, p. 67).

Do mesmo modo, segundo Ribeiro, o conceito de cidades fraturadas ${ }^{8}$, nas quais os espaços se justapõem, mas são regidos por lógicas diferenciadas, também não tem sido confirmado por outros estudos empíricos ${ }^{9}$. Estes têm verificado, com freqüência, que as "desigualdades e diferenças estão reproduzidas em todo o território da cidade" (Ribeiro, 2000b, p. 69), sendo raras as hierarquias graduais entre as diferentes áreas das cidades.

No caso da cidade do Rio de Janeiro, foi desenvolvida uma detalhada pesquisa, pelo Instituto de Planejamento Urbano e Regional (IPPUR), da UFRJ, com base no Censo de 1991 (Ribeiro, 2000b). O espaço metropolitano carioca foi discretizado em bairros e agrupados em três distintos tipos de espaços, denominados superiores, médios e inferiores. A análise de quem habita estes espaços, surpreendentemente, revelou os seguintes resultados principais: não se verificou um efeito de dualização da estrutura social (crescimento das categorias superiores e populares e diminuição das categorias médias), mas um aumento significativo da pequena burguesia, bem como das categorias médias (mesmo que menos expressivo); em todas as regiões da cidade, encontrou-se uma presença expressiva das categorias médias e inferiores da população, contrariando a tese da cidade partida, por fim, verificou-se que, apesar da hierarquização dos espaços, não há uma segregação ou exclusão das camadas mais pobres, localizáveis, por seu turno, mesmo que em proporções diferentes, por toda a região metropolitana.

\section{CONSIDERAÇÕES FINAIS}

A análise histórica dos diversos sentidos que a desigualdade tem assumido no discurso acadêmico, abordado ao longo deste trabalho, permite-nos alertar para a necessidade de estudos mais amplos, sobre a questão. Os diversos usos abrangentes e pouco precisos que os conceitos de marginalidade, segregação, desigualdade e exclusão tomaram ao longo dos últimos 30 anos, ao sabor de uma literatura crítica, mas nem por isso imune às ingerências das conjunturas e dos instrumentais teóricos disponíveis, devem servirnos de alerta, em relação a afirmações apressadas 
sobre a complexidade do contexto atual.

Especialmente a última pesquisa citada (Ribeiro, 2000b), sobre a cidade do Rio de Janeiro, remete-nos à questão de que a exclusão social e seus entornos devem ser analisados em cada uma de suas múltiplas facetas - tensões na governabilidade, falta de mobilidade social, exclusão de cidadania, segregação espacial e outros -, de forma cuidadosa e atenta às diversas escalas - locais ou globais - sobre as quais se pode projetar a investigação, evitando, assim, as grandes generalizações que parecem ser atraídas pelo fenômeno de globalização da economia. Como bem disse o professor Milton Santos:

Quanto mais os lugares se mundializam, mais se tornam singulares e específicos, isto é, "únicos". Isto se deve à especialização desenfreada dos elementos do espaço - homens, firmas, instituições, meio ambiente -, à dissociação sempre crescente dos processos e subprocessos necessários a uma maior acumulação de capital, à multiplicação das ações que fazem do espaço um campo de forças multidirecionais e multicomplexas, onde cada lugar é extremamente distinto do outro, mas também claramente ligado a todos os demais ... (Santos, 1997, p. 34)

Enfim, o que queremos argumentar é que a realidade urbana, dependendo da escala de análise que adotemos, pode ser surpreendente, acolhendo situações que pareceriam excludentes e inconciliáveis. Ao que tudo indica, a história de cada cidade tem um peso fundamental no desenvolvimento de sua ocupação, não se verificando, pelo menos até o momento, um destino único para todas as cidades globais. Desvelar e entender que homens se constituem e sobrevivem neste emaranhado de fios de tantas espessuras, tamanhos e rugosidades é o que move muitos de nós psicólogos, historiadores, antropólogos, sociólogos, urbanistas, geógrafos e tantos outros -, que se apaixonaram pelo urbano, pelas cidades e seus habitantes, com todas as suas idiossincrasias e previsibilidades.

\section{NOTAS}

1 Berlink (1975) menciona as seguintes publicações de José Nun e Anibal Quijano: "Superpopulación relativa, ejército industrial de reserva y masa marginal, Revista Latino-Americana de Sociologia, v. 5, n. 2, jul/1969" e "Redefinición de la dependencia y marginalización en América Latina, Santiago, Facultad de Ciencias Económicas, Universidade de Chile, 1970", respectivamente.

2 Discorrendo sobre a abrangência e imprecisão do conceito, Kowarick (1975) defende que a marginalidade não deveria ser caracterizada em função da hierarquização na participação das riquezas econômicas e sociais produzidas pela sociedade, mas tão somente em termos da inserção ou não dos trabalhadores no sistema produtivo. Neste sentido, não se trata de entender por marginais os grupos sociais presentes nos níveis mais baixos da economia, adotando-se critérios como, por exemplo, a baixa remuneração, uma vez que a exclusão assim definida, abrangendo "um processo demasiadamente genérico ..., perde seu processo explicativo" (p. 103).

3 É preciso destacar, no entanto, que para Castel (1998), a exclusão é uma situação limite, pois é antecedida por zonas intermediárias de vulnerabilidade ou de assistência.

4 Há que se chamar atenção para o uso exacerbado do "rótulo" exclusão social, pois a coisificação do conceito pode mimetizar a realidade e funcionar muito mais como uma indução a práticas imobilizantes.

5 O termo foi primeiramente utilizado por Saskia Sassen (1998).

6 A este respeito, Nascimento (1994) aborda que o papel do Estado em assegurar as "condições mínimas de sobrevivência, de participação política e de liberdade de lutar para mudar sua sorte" (p. 293), necessárias à mobilidade social, coloca em cena uma questão da globalização, qual seja a crise da governabilidade dos estados nacionais, deflagrada a partir do conflito de interesse entre os Estados e as firmas multinacionais.

7 Ribeiro (2000a) cita os trabalhos de Hamnett (1995) e de Preteceille $(1993,1995)$.

8 Ribeiro (2000b) cita o trabalho Dual cities. New York: The Russem Foundation, 1991, dos autores Mollenkopf e Castells (1991), que cunham o conceito de dual cities, definindo a ocorrência de uma fragmentação da ordem sócio-espacial nas cidades pósindustriais. que teria como base a coexistência de duas lógicas de organização do território - segregação e diferenciação. A primeira, organizada por um "misto de mercado e de normas institucionais", conformaria a ocupação das classes alta e baixa (topo e base da pirâmide social), enquanto que a diferenciação "fundamenta-se na distribuição dos segmentos médios pelo espaço metropolitano por meio do mecanismo do mercado imobiliário" (Ribeiro, 2000b, p. 68).

9 Ribeiro (2000b) cita os estudos de Preteceille (1993), mencionados anteriormente.

\section{REFERÊNCIAS}

Arendt, H. (1990). As origens do totalitarismo. São Paulo: Companhia das Letras.

Berlink, M. (1975). Marginalidade social e relações de classes em São Paulo. Petrópolis, RJ: Vozes. 
Castel, R. (1998). As metamorfoses da questão social. Petrópolis, RJ: Vozes.

Kowarick, L. (1975). Capitalismo e marginalidade na América Latina (2a. ed.). São Paulo: Paz e Terra.

Nascimento, E. (1994). A exclusão social na França e no Brasil: situações (aparentemente) invertidas, resultados (quase) similares. Em E. Diniz (Org.), O Brasil no rastro da crise (pp. 289-303). São Paulo: ANPOCS/ IPEA/ Hucitec.

Quijano, A. (1978). Notas sobre o conceito de marginalidade. Em L. Pereira (Org.), Populações marginais. São Paulo: Duas Cidades.

Ribeiro, L. C. Q. (2000a). Introdução. L. C. Q. Ribeiro (Org.), O futuro das metrópoles: desigualdades e governabilidade (pp. 11-18). Rio de Janeiro: Editora Revan / FASE.

Ribeiro, L. C. Q. (2000b). Cidade desigual ou cidade partida? Tendências da metrópole do Rio de Janeiro. Em L. C. Q. Ribeiro (Org.), O futuro das metrópoles: desigualdades e governabilidade (pp. 63-98). Rio de Janeiro: Revan / FASE.

Santos, B. S. (1999). Reinventar a democracia. Em A. Heller (Org.), A crise dos paradigmas em Ciências Sociais e os desafios para o século XXI (pp. 33-75). Rio de Janeiro: Contraponto.

Santos, M. (1987). O espaço do cidadão. São Paulo: Nobel.

Santos, M. (1997). Metamorfoses do espaço habitado (5ª ed.). São Paulo: Hucitec.

Sassen, S. (1998). The global city: New York, London,
Tokyo. New Jersey: Princeton University Press.

Véras, M. (1999). Exclusão social: um problema brasileiro de 500 anos. Em B. Sawaia (Org.), As artimanhas da exclusão: análise psicossocial e ética da desigualdade social (pp. 27-50). Petrópolis, RJ: Vozes.

Ana Lúcia Gonçalves Maiolino é Doutora em Psicologia Social (UERJ), Pós-doutoranda (PRODOC)

do Programa de Pós-graduação em Psicologia Social da Universidade do Estado do Rio de Janeiro e Professora Visitante da Universidade do Estado do Rio de Janeiro. Endereço para correspondência: Rua Silveira Martins 150, 203, 22221000 Catete, Rio de Janeiro, $R J$ E-mail: anamaiolino@br.inter.net; mancebo@uerj.br

Deise Mancebo é Doutora em História (PUC-SP), com Pós-doutorado em Psicologia Social (USP), Professora Titular de Psicologia Social, Pesquisadora do Programa de Políticas Públicas e Formação Humana e do Programa de Psicologia Social da Universidade do Estado do Rio de Janeiro (UERJ). Endereço para correspondência: Pós-Fraduação em Psicologia Social. Rua São Francisco Xavier, 524/10 ${ }^{\circ}$ andar sala 10019, Bloco F - Maracanã - Rio de Janeiro, CEP 20559-900

E-mail: mancebo@uerj.br

\author{
Ana Lúcia Gonçalves Maiolino e \\ Deise Mancebo \\ Análise histórica da desigualdade: \\ marginalidade, segregação e exclusão. \\ Recebido: 16/06/2005 \\ $1^{\mathrm{a}}$ revisão: 30/09/2005 \\ Aceite final: 25/10/2005
}

